\title{
Mechanical Properties and Hydrogen Embrittlement of Laser-Surface Melted AISI 430 Ferritic Stainless Steel
}

\author{
W. K. Chan ${ }^{1}$, C. T. Kwok ${ }^{1,2, *}$ and K. H. Lo ${ }^{1,2}$ \\ 1 Department of Electromechanical Engineering, Faculty of Science and Technology, University of Macau, \\ Macau 999078, China; ericchan@um.edu.mo (W.K.C.); fstkhl@um.edu.mo (K.H.L.) \\ 2 Institute of Applied Physics and Materials Engineering, University of Macau, Macau 999078, China \\ * Correspondence: fstctk@um.edu.mo
}

Received: 7 January 2020; Accepted: 1 February 2020; Published: 4 February 2020

\begin{abstract}
In the present study, the feasibility of laser surface melting (LSM) of AISI 430 ferritic stainless steel to minimize hydrogen embrittlement (HE) was investigated. LSM of AISI 430 steel was successfully achieved by a 2.3-kW high power diode laser (HPDL) with scanning speeds of $60 \mathrm{~mm} / \mathrm{s}$ and $80 \mathrm{~mm} / \mathrm{s}$ (the samples are designated as V60 and V80, respectively) at a power of $2 \mathrm{~kW}$. To investigate the HE effect on the AISI 430 steel without and with LSM, hydrogen was introduced into specimens by cathodic charging in $0.1 \mathrm{M} \mathrm{NaOH}$ solution under galvanostatic conditions at a current density of $30 \mathrm{~mA} / \mathrm{cm}^{2}$ and $25^{\circ} \mathrm{C}$. Detail microstructural analysis was performed and the correlation of microstructure with HE was evaluated. By electron backscatter diffraction (EBSD) analysis, the austenite contents for the laser-surface melted specimens V60 and V80 are found to be 0.6 and $1.9 \mathrm{wt} \%$, respectively. The amount of retained austenite in LSM specimens was reduced with lower laser scanning speed. The surface microhardness of the laser-surface melted AISI 430 steel $\left(\sim 280 \mathrm{HV}_{0.2}\right)$ is found to be increased by $56 \%$ as compared with that of the substrate $\left(\sim 180 \mathrm{HV}_{0.2}\right)$ because of the presence of martensite. The degree of embrittlement caused by hydrogen for the charged and non-charged AISI 430 steel was obtained using slow-strain-rate tensile (SSRT) test in air at a strain rate of $3 \times 10^{-5} \mathrm{~s}^{-1}$. After hydrogen pre-charging, the ductility of as-received AISI 430 steel was reduced from 0.44 to 0.25 while the laser-surface melted AISI 430 steel showed similar tensile properties as the as-received one. After LSM, the value of HE susceptibility $I_{\delta}$ decreases from $43.2 \%$ to $38.9 \%$ and $38.2 \%$ for V60 and V80, respectively, due to the presence of martensite.
\end{abstract}

Keywords: laser surface melting; ferritic stainless steel; hydrogen embrittlement; mechanical properties

\section{Introduction}

Hydrogen is the most available renewable energy for its abundance. In addition, only water vapor is produced from hydrogen reaction. Thus, hydrogen energy is considered as the cleanest energy source [1]. Hydrogen energy is also recognized to be one of the most suitable solutions to the environmental problems nowadays if it is produced from renewable resources. Owing to excellent corrosion performance of stainless steels, they are widely used in power and nuclear plants as hydrogen storage vessels. During storage of hydrogen in metallic vessels, the most critical issues are the adsorption/desorption and permeation of hydrogen in the metallic materials, as well as possible hydrogen embrittlement (HE). In particular, ferritic and austenitic stainless steels and nickel-based alloys exhibit a minimum ductility at a specific temperature not far from room temperature. It is a serious problem for the use of these alloys as storage tank for fuel cells used in automotive applications [2-6]. 
Due to the low nickel content, the ferritic stainless steels (FSSs) are generally cheaper than the austenitic stainless steels. However, the diffusion coefficient of hydrogen in the ferrite and hence the hydrogen permeation rate are higher than those of the austenite [7,8]. Thus, FSSs are more susceptible to HE.

In the literature, various methods of surface modification have been attempted to minimize the effects of $\mathrm{HE}$ on stainless steels. Electroplated $\mathrm{Zn}, \mathrm{Ni}, \mathrm{Cu}, \mathrm{Al}$, PVD-Ti-DLC, electroless NiP coatings, as well as carbon, nitrogen, and oxygen diffusion layers were investigated for their suitability to reduce HE of AISI 304 by Michler and Naumann [9]. However, none of the coatings significantly improved the tensile ductility (elongation or reduction of area) in hydrogen atmosphere compared to the untreated specimens. The main failure mechanisms were a very low fracture strain of the coatings as well as insufficient adhesion and coating defects. HE always starts at such imperfections. In addition, the nitrogen and carbon diffusion layers reduced crack propagation in $\mathrm{H}_{2}$ atmosphere but quasi-cleavage fracture still occurred in these layers.

Generally, cracking caused by HE often occurs in stress concentrated regions in some engineering components, such as a turbine, a pipe, and so on. Therefore, if only the stress concentrated region can be softened locally, then hydrogen-induced cracking can be effectively avoided with little sacrifice to the strength of the alloys. Owing to the high controllability and high energy density, laser beam is a feasible energy source that can locally heat the surface regions where hydrogen-induced cracking is liable to occur. Nowadays, laser surface modification is widely used in surface engineering, including laser transformation hardening (LTH), laser surface melting (LSM), laser surface alloying (LSA), and laser cladding (LC) [10]. LSM is a rapid solidification process which can achieve the formation of metastable phases, homogenization and refinement of microstructure, and dissolution/redistribution of precipitates or inclusions, while the bulk properties can be preserved. It brings great economic and social benefits, including lower energy consumption, reduction of pollution, saving precious materials, and high-value is added to the engineering components. It also has been proven to be a promising method for improving corrosion, wear, and fatigue resistances of a wide range of engineering alloys [11]. Conde and his co-workers [12] reported that the laser processing parameters were critical to corrosion behavior of laser-surface melted AISI 430 FSS. To the best of the present authors' knowledge, no study on the effect of laser surface modification on the HE behavior of FSS has been reported in the literature. In the present study, the feasibility of LSM of AISI 430 FSS by a 2.3-kW high power diode laser (HPDL) with different processing conditions for mitigating HE was investigated. After LSM, detailed microstructural analysis was performed and the correlation with HE was evaluated.

\section{Experimental Details}

The as-received (AR) AISI 430 steel in plate form was cut into specimens with dimensions of $110 \times$ $30 \times 4 \mathrm{~mm}^{3}$. The gauge length of the tensile specimens was $50 \mathrm{~mm}$ in rectangular shape. The nominal chemical compositions of AISI 430 steel are shown in Table 1.

Table 1. Chemical compositions of AISI 430 ferritic stainless steel (FSS).

\begin{tabular}{ccccccccc}
\hline Element & Fe & Cr & Ni & Mn & Si & C & P & S \\
\hline wt- $\%$ & Bal. & 16.1 & 0.10 & 0.29 & 0.224 & 0.12 & 0.019 & 0.004 \\
\hline
\end{tabular}

In the present study, the feasibility of LSM of AISI 430 steel for minimizing HE was investigated. To study the HE effect on the AISI 430 steel without and with LSM, hydrogen was introduced into the specimens by cathodic charging under galvanostatic conditions by a DC power supply. The setup of hydrogen pre-charging of AISI 430 steel is shown in Figure 1a. A graphite electrode was connected to the positive lead of the power supply and the specimen was connected to the negative lead in the $0.1 \mathrm{M} \mathrm{NaOH}$ solution at $25^{\circ} \mathrm{C}$ at a current density of $30 \mathrm{~mA} / \mathrm{cm}^{2}$ for one week. $\mathrm{NaOH}$ solution was used instead of $\mathrm{H}_{2} \mathrm{SO}_{4}$ solution because of the more effective charging effect of the former as reported by Zakroczymsk [13]. 


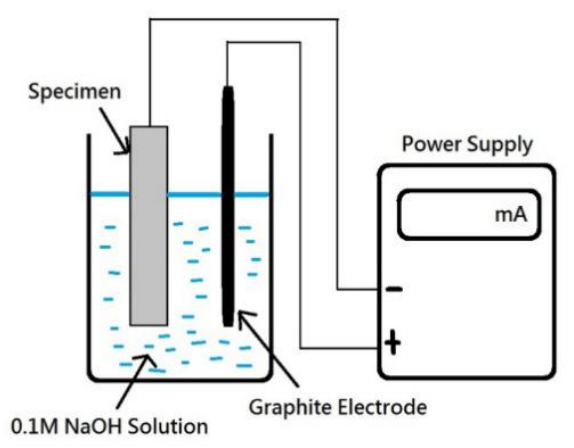

(a)

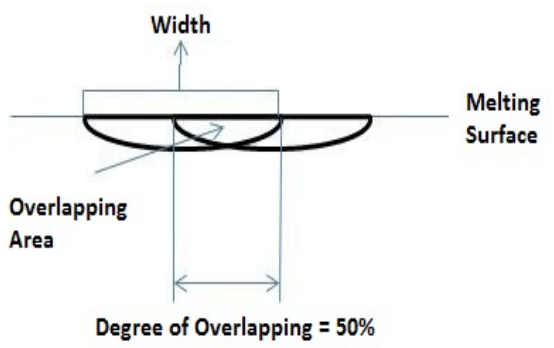

(c)

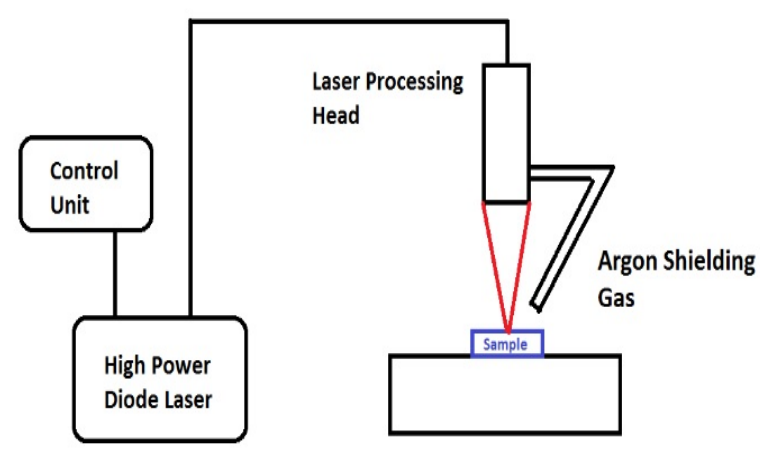

(b)

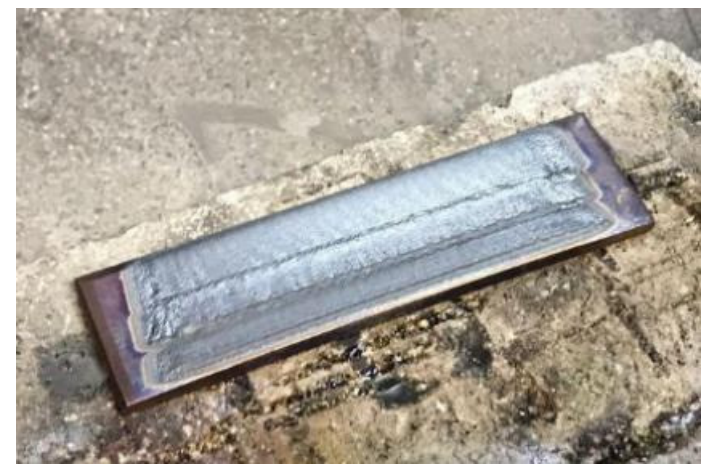

(d)

Figure 1. Schematic diagrams of (a) setup of hydrogen pre-charging of AISI 430 steel, (b) setup of laser surface melting (LSM) of AISI 430 steel, (c) overlapping of successive tracks by LSM, and (d) sample fabricated by LSM for hydrogen pre-charging and tensile testing.

LSM of AISI 430 steel was carried out using a 2.3-kW continuous wave (CW) HPDL with a power of $2 \mathrm{~kW}$, a beam diameter of $2 \mathrm{~mm}$, and various scanning speeds ( 60 and $80 \mathrm{~mm} / \mathrm{s}$ ). The specimens were designated as V60 and V80, respectively. The schematic diagram of the LSM setup of AISI 430 steel is shown in Figure 1b. Argon flowing at $15 \mathrm{~L} / \mathrm{min}$ was used as the shielding gas. The laser-surface melted specimens were achieved by overlapping the parallel tracks with an overlapping degree of $50 \%$ (Figure 1c). A laser-surface melted specimen for hydrogen pre-charging and tensile testing is shown in Figure $1 \mathrm{~d}$. The investigation conditions of the samples for the present study are tabulated in Table 2:

Table 2. Investigation conditions for AISI 430 steel: $M$ stands for microstructural analysis, $X$ stands for XRD analysis, $\mathrm{H}$ stands for microhardness test, $\mathrm{T}$ stands for tensile test, and $\mathrm{F}$ stands for fractography analysis.

\begin{tabular}{lccc}
\hline & (i) As-received & (ii) V60 & (iii) V80 \\
\hline (a) Without hydrogen pre-charging & $\mathrm{M} / \mathrm{X} / \mathrm{H} / \mathrm{T} / \mathrm{F}$ & $\mathrm{M} / \mathrm{X} / \mathrm{H} / \mathrm{T} / \mathrm{F}$ & $\mathrm{M} / \mathrm{X} / \mathrm{H} / \mathrm{T} / \mathrm{F}$ \\
(b) With hydrogen pre-charging & $\mathrm{T} / \mathrm{F}$ & $\mathrm{T} / \mathrm{F}$ & $\mathrm{T} / \mathrm{F}$ \\
\hline
\end{tabular}

The laser-surface melted specimens were cross-sectioned, mechanically ground, polished, and then etched. The microstructure and phases of the specimens were analyzed using a field emission scanning-electron microscope (FESEM, Zeiss Zigma, Jena, Germany) equipped with an electron backscatter diffraction (EBSD, Oxford, Abingdon, U.K.) detector, and X-ray diffractometry (XRD, Rigaku MiniFlex 600, Tokyo, Japan). The radiation source of the XRD was $\mathrm{Cu} \mathrm{K} \alpha$ with Ni filter and generated at $600 \mathrm{~W}$. The scan rate used was $0.1 \%$ s. 
Microhardness measurements were conducted along the melt zones longitudinally using a Vickers hardness tester (VH3100, Buehler, Esslingen, Germany) with a load of $200 \mathrm{~g}$ and a loading time of $10 \mathrm{~s}$. The degree of embrittlement caused by hydrogen for the laser-surface melted specimens without and with hydrogen pre-charging were assessed using slow-strain-rate tensile (SSRT) tests in air at a strain rate of $3 \times 10^{-5} \mathrm{~s}^{-1}$ at $25^{\circ} \mathrm{C}$ according to ASTM standard G129-00 [14]. To investigate the HE susceptibility, the relative plastic loss $I_{\delta}$ is defined as the HE susceptibility [15]:

$$
I_{\delta}=\left(1-\frac{I_{H C}}{I_{U C}}\right) \times 100 \%
$$

where $I_{H C}$ and $I_{U C}$ are the elongation of the hydrogen pre-charged and uncharged specimens, respectively. The fracture morphologies of the laser-surface melted and as-received specimens after the SSRT tests were studied by the FESEM.

The investigation conditions of the samples without hydrogen pre-charging are shown in Table 2a. Three samples were tested for each set of measuring conditions for XRD analysis, tensile and microhardness testing (with error measurements) to ensure the repeatability of the results. One sample was selected for microstructural analysis and fractography analysis (both were studied using FESEM), while the investigation conditions for the samples with hydrogen pre-charging are shown in Table $2 \mathrm{~b}$. Three samples were taken for each set of measuring conditions for the tensile test and one sample was selected for fractography analysis using FESEM.

\section{Results and Discussion}

\subsection{Microstructural Analysis}

The cross-sections and microstructures of the laser-surface melted AISI 430 steel fabricated at different processing speeds $(60 \mathrm{~mm} / \mathrm{s}$ and $80 \mathrm{~mm} / \mathrm{s})$ under different magnifications are shown in Figure 2. The as-received AISI 430 steel contains a fully ferritic phase (confirmed by XRD as shown in Figure 3) with an average grain size of $15 \mu \mathrm{m}$. After LSM, the grain size of the ferrite in the melt zone (MZ) is considerably increased to $57 \mu \mathrm{m}$ (V80) and to $67 \mu \mathrm{m}(\mathrm{V} 60)$, while the grain size in the heat-affected zone (HAZ) is smaller ( $44 \mu \mathrm{m}$ for V80 and $48 \mu \mathrm{m}$ for V60). This structure of the ferrite has a polygonal morphology and the white phases at the grain boundaries are mainly martensite [Figure 2a(ii),b(ii)]. A tiny amount of retained austenite was detected using EBSD (Table 3).

Compared with the laser-surface melted specimen at lower scanning speed (V60), a smaller grain size was observed for V80 (fabricated at higher scanning speed) as shown in Table 3. At a higher scanning speed (V80), the interaction time between the laser and the material was shorter leading to a higher quenching rate and hence a smaller grain size in the MZ. Grain size is expected to be controlled by applying high scanning speed (lower heat input) during LSM in order to keep the mechanical strength of AISI 430 steel.

The thickness and grain size of the MZ and HAZ for the laser-surface melted specimens decrease as the scanning speed increases (Table 3). The thicknesses for V60 and V80 of the MZ are quite close. Conde and his co-workers reported that the austenite started to appear in the interdendritic region in form of Widmanstatten austenite platelets [12] as in V60 and V80. At higher laser scanning speed (V80), the volume fraction of austenite is higher. Since the austenite is less prone to hydrogen diffusion $[7,8]$, the presence of austenite in the laser-surface melted specimens may delay the hydrogen diffusion. From Figure $2 \mathrm{a}(\mathrm{i}), \mathrm{b}(\mathrm{i})$, a narrow HAZ can be observed in which fewer martensites are present along ferrite grain boundaries.

For investigating the cooling effects on the stainless steels, the primary solidification mode was determined by the modified Schaeffter diagram [16]. The chromium equivalent $\left(\mathrm{Cr}_{\mathrm{eq}}\right)$ and nickel equivalent $\left(\mathrm{Ni}_{\mathrm{eq}}\right)$ [17] are defined below:

$$
\mathrm{Cr}_{\mathrm{eq}}=[\mathrm{Cr}]+[\mathrm{Mo}]+1.5[\mathrm{Si}]+0.5[\mathrm{Nb}]
$$




$$
\mathrm{Ni}_{\mathrm{eq}}=[\mathrm{Ni}]+30[\mathrm{C}]+30[\mathrm{~N}]+0.5[\mathrm{Mn}] .
$$

Since the $\mathrm{Cr}_{\mathrm{eq}} / \mathrm{Ni}_{\text {eq }}$ ratio of AISI 430 steel is high $(16.436 / 3.845=4.27)$, the formation tendency of $\delta$-ferrite is very high. Through a primary ferrite solidification mode, the laser-surface melted AISI 430 steel mainly possesses columnar grains of primary $\delta$-ferrite [Figure 2a] with a small amount of intergranular martensite $\left(\alpha^{\prime}\right)$ /austenite $(\gamma)$ formed at boundaries of $\delta$ grains as the minor phases (Figure 2a(ii),b(ii)). From the pseudo-binary phase diagram of Fe-C at $17 \%$ Cr [18], a major ferritic microstructure can be achieved by suppressing the austenite formation at elevated temperatures. As the melt pools of the laser-melted specimens solidify, the sequence of phase transformation upon cooling is the primary solidification of $\delta$ :

$$
\mathrm{L} \rightarrow \mathrm{L}+\delta \rightarrow \delta \rightarrow \delta+\gamma \rightarrow \delta+\alpha^{\prime}
$$

After LSM, $\delta$-ferrite is the first phase to solidify followed by partial transformation from $\delta$-ferrite to austenite during cooling. Under a non-equilibrium cooling condition (i.e., LSM), martensite was formed at the grain boundaries by solid-state transformation of austenite [18]. It is reported that the microstructure of AISI 430 steel is significantly affected by the laser processing conditions (i.e., scanning speed and power density); hence, the cooling rate [12]. Similar microstructures (primary $\delta$ with a small amount of intergranular martensite) were observed in AISI 430 steel [16].

Martensite was detected at the grain boundaries of the ferritic grains. The martensite formation in the melt zone of laser-surface melted AISI 430 steel can be predicted from the chemical compositions using the Kaltenhauser ferrite factor (KFF) [19]:

$$
\mathrm{KFF}=[\mathrm{Cr}]+6[\mathrm{Si}]+8[\mathrm{Ti}]+4[\mathrm{Mo}]+2[\mathrm{Al}]-40[\mathrm{C}+\mathrm{N}]-2[\mathrm{Mn}]-4[\mathrm{Ni}]
$$

It is reported that the formation of martensite during the welding of FSS can be avoided if its KFF factor is larger than 17 [18]. In the present study, the KFF of AISI 430 steel was calculated to be 11.7. Martensite was observed in the melt zone of the laser-surface melted specimens (Figure 2). However, the KFF did not reflect the martensite content in the laser-surface melted specimens. Thus, the Balmforth diagram was used to predict the microstructure of the laser-surface melted AISI 430 steel $[18,20]$. From Figure $2 a(i i), b(i i)$, the major columnar $\delta$-ferritic structure with a small amount of martensite $(4.8 \%-5.4 \%$ ) and austenite (less than $2 \%$ ) can be observed. It is in accordance with the prediction using the Balmforth diagram.

The XRD patterns of the as-received and laser-surface melted specimens are shown in Figure 3. From Figure 3a, only $\alpha$-ferrite was detected in the as-received AISI 430 steel. The peaks for $\delta$-ferrite and martensite in the laser-surface melted specimens are overlapped and cannot be distinguished. For V60, the main phase detected was $\delta$-ferrite/martensite and a very small peak of austenite $(\gamma)$ was detected at $50.7^{\circ}$ (Figure 3b). For V80, more significant austenite peaks were detected at $43.5^{\circ}$ and $50.7^{\circ}$ due to the higher processing speed (Figure 3c). The existence of austenite depicted in the XRD patterns was consistent with the austenite detected using EBSD. From the EBSD results, a small amount of austenite can be observed in the laser-surface melted specimens. The corresponding austenite contents for V60 and V80 are found to be 0.6 and $1.9 \mathrm{wt} \%$, respectively. At a higher laser processing speed, the quenching rate is higher, the time for austenite-ferrite transformation decreased, and the volume fraction of retained austenite increases. The result is supported by Conde et al. [12] and Colacë and Vilar [21]. From Conde and his co-workers' research [12], it was reported that the retained austenite increased as the laser scanning speed increased. From Colacë and Vilar's research [21], the amount of retained austenite in the laser-surface melted FSS was reduced by decreasing the laser scanning speed and increasing the laser power density. Their studies are consistent with the present EBSD results. 


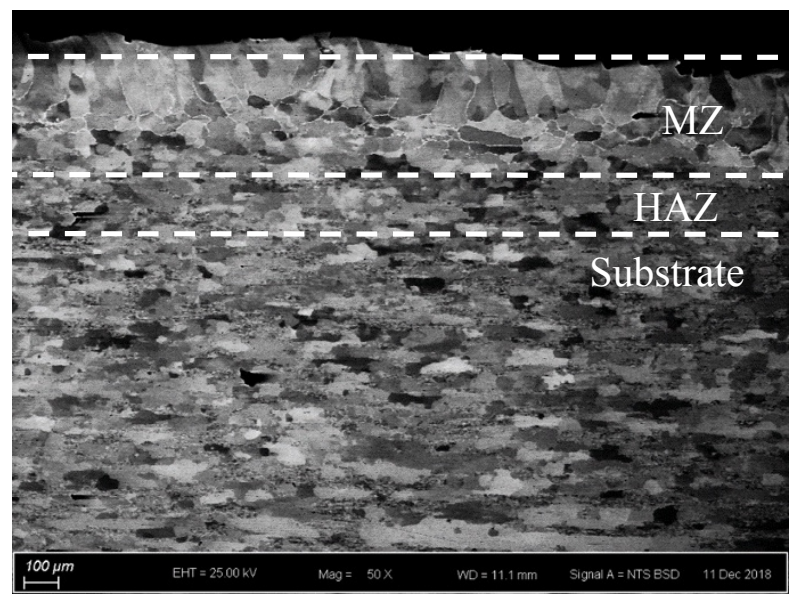

(a)(i)

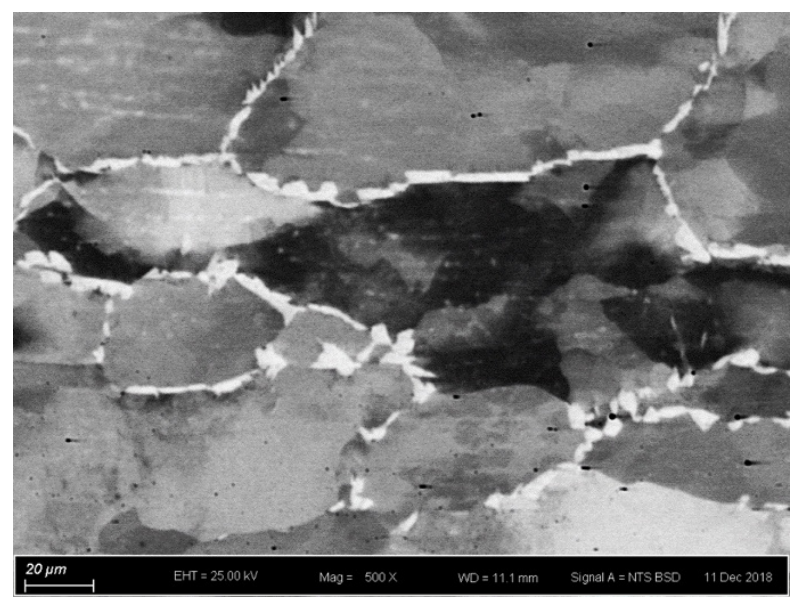

(a) (ii)

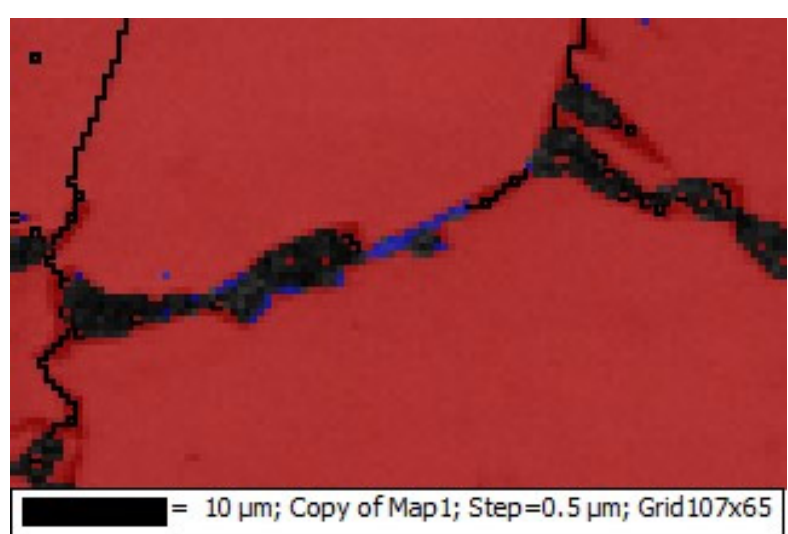

(a)(iii)

Figure 2. Cont. 


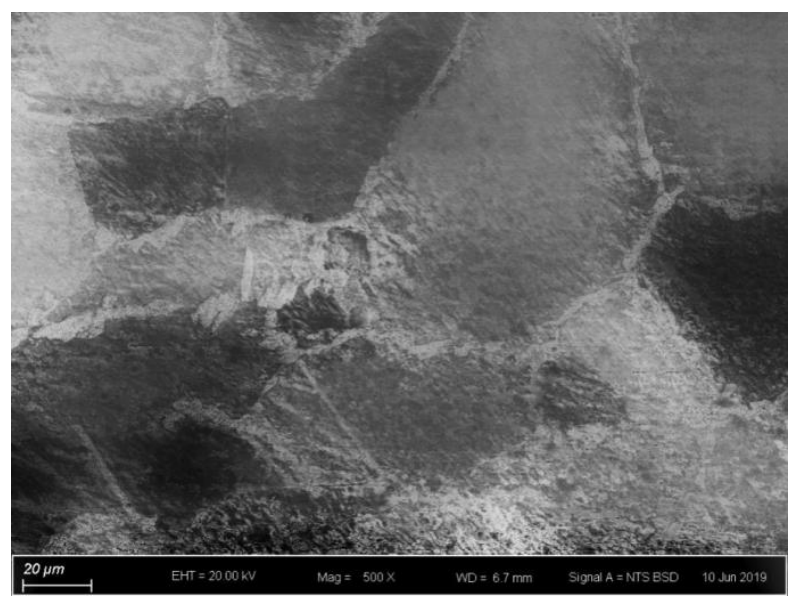

(a)(iv)

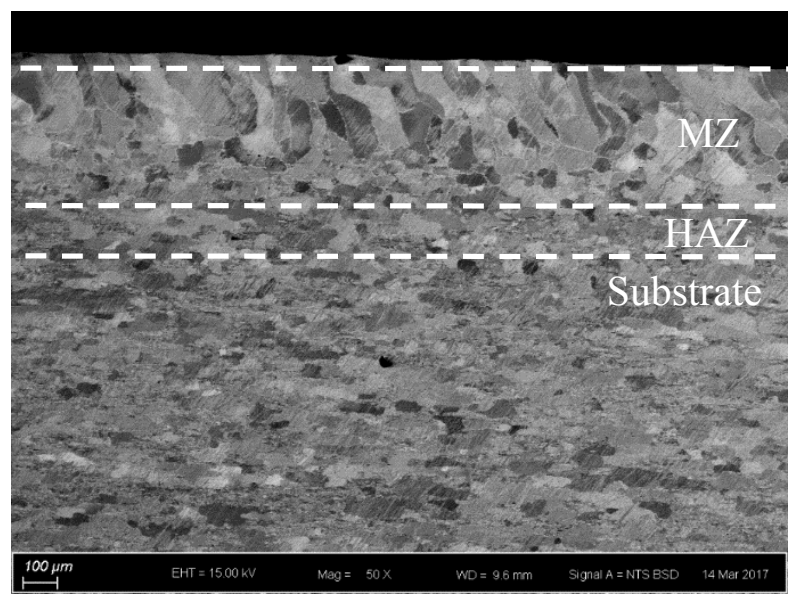

(b)(i)

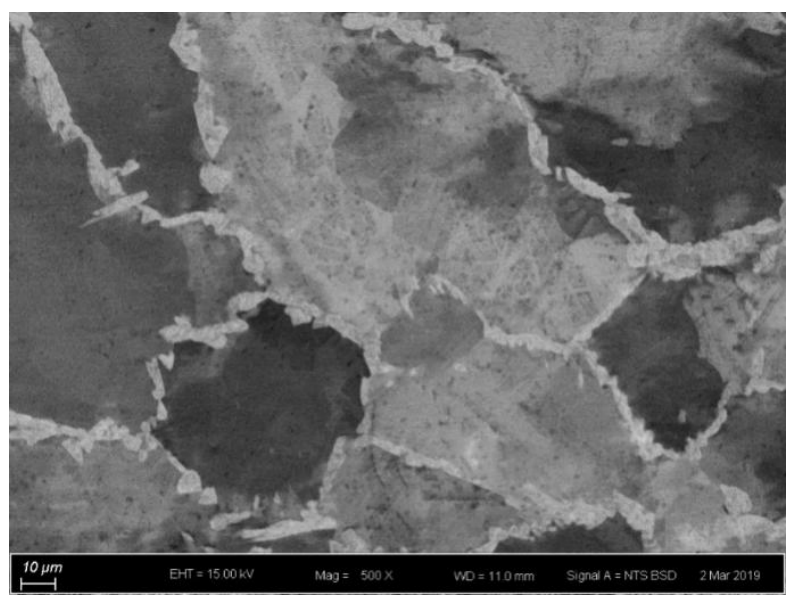

(b)(ii)

Figure 2. Cont. 


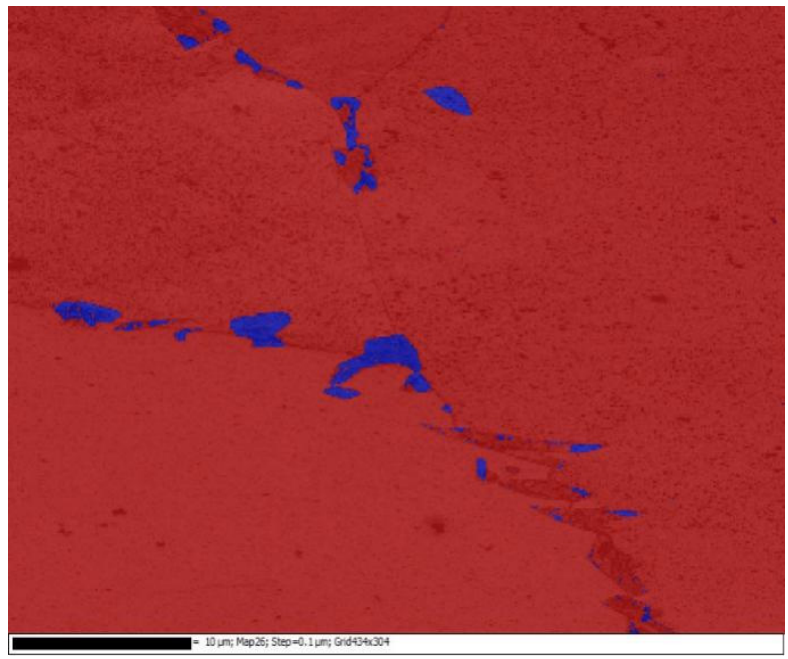

(b)(iii)

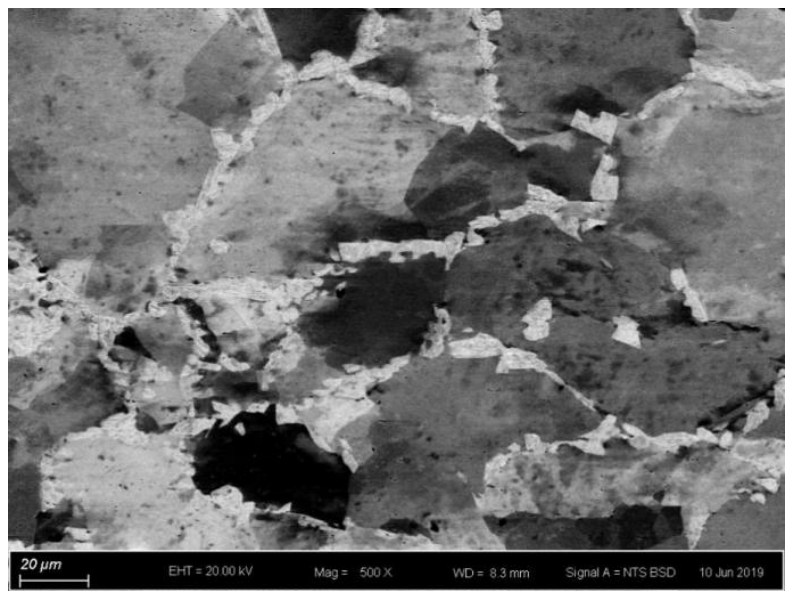

(b)(iv)

Figure 2. The laser-surfaced melted specimens: (a) V60 and (b) V80; (i) cross-sectional views (50×), (ii) microstructure of melt zone (MZ); (iii) electron backscatter diffraction (EBSD) phase maps of MZ (blue phase is for austenite and red phase is for ferrite); and (iv) microstructure of heat-affected zone (HAZ).

Table 3. Average grain size of ferrite, martensite, and austenite contents, thickness of MZ and HAZ of the as-received AISI 430 steel, laser-surface melted specimens V60 and V80.

\begin{tabular}{cccc}
\hline & As-Received Steel AISI 430 & V60 & V80 \\
\hline Average grain size of ferrite in substrate $(\mu \mathrm{m})$ & $15 \pm 2$ & - & - \\
\hline Average grain size of ferrite in $\mathrm{MZ}(\mu \mathrm{m})$ & - & $67 \pm 41$ & $57 \pm 29$ \\
\hline Average grain size of ferrite in $\mathrm{HAZ}(\mu \mathrm{m})$ & - & $48 \pm 7$ & $44 \pm 4$ \\
\hline Martensite content $(\%)$ & 0 & 5.4 & 4.8 \\
\hline Austenite content $(\%)$ & 0 & 0.6 & 1.9 \\
\hline Thickness of MZ $(\mu \mathrm{m})$ & N/A & $264 \pm 20$ & $255 \pm 18$ \\
\hline Thickness of $\mathrm{HAZ}(\mu \mathrm{m})$ & N/A & $74 \pm 11$ & $77 \pm 7$ \\
\hline
\end{tabular}




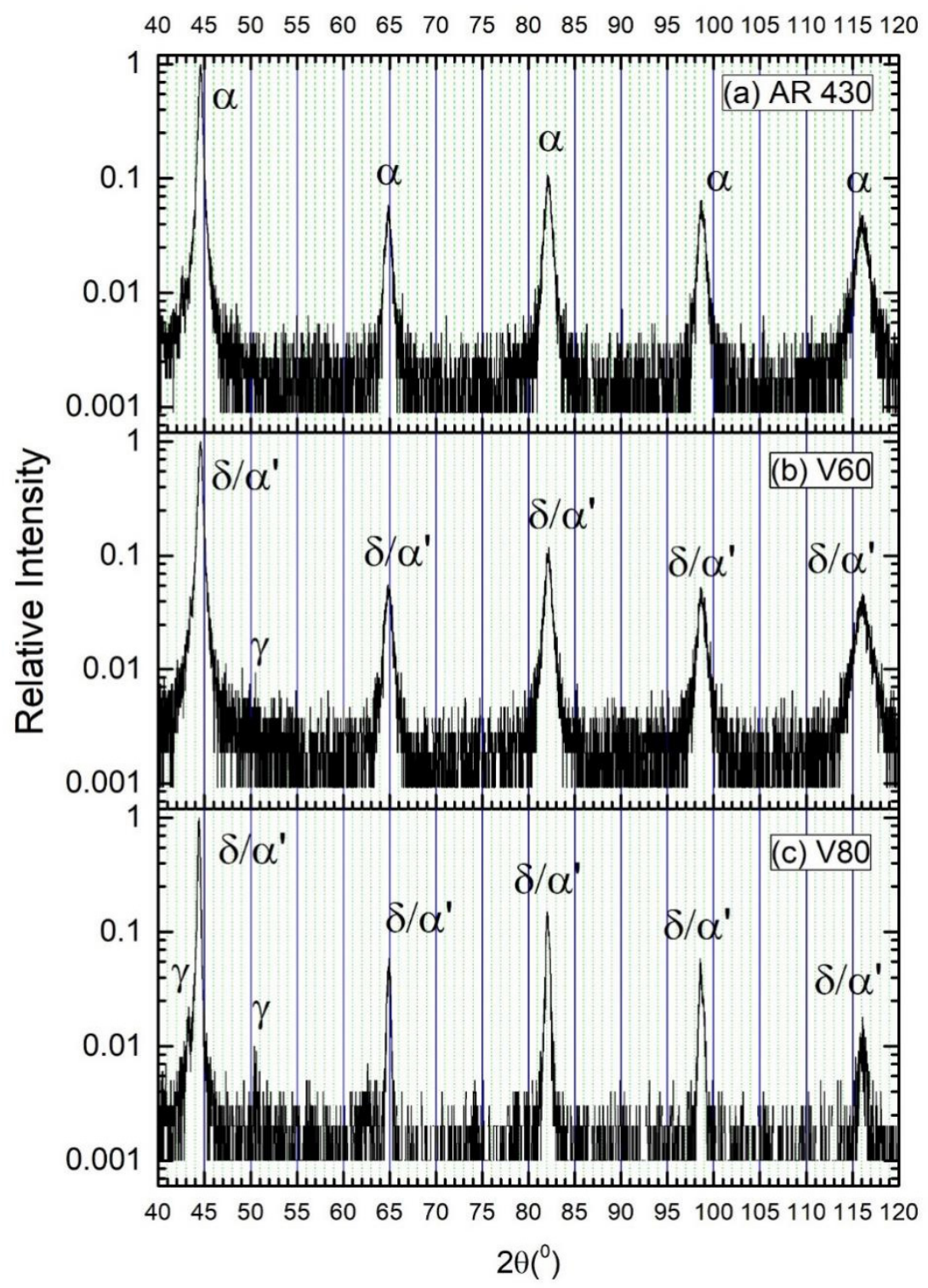

Figure 3. XRD patterns of (a) as-received AISI 430 steel, (b) V60, and (c) V80 before hydrogen charging.

\subsection{Microhardness}

The microhardness profiles along the cross-section of the laser-surface melted specimens V60 and V80 are shown in Figure 4. The width of the MZ is about $250 \mu \mathrm{m}$, the microhardness is in the range of 270-290 $\mathrm{HV}_{0.2}$. Despite the larger grain size, the laser-surface melted AISI 430 steel (V60 and V80) has a significant increase in microhardness owing to the formation of martensite. This result is supported by Sundqvist and his co-workers [22]. Compared with the substrate, the MZ microhardness of the laser-surface melted specimens is increased by $56 \%$. Compared with V60, lower microhardness was found at the MZ for V80 due to higher austenite content. The result is also supported by Khorram and his co-workers [23], who reported that the increase in martensite content (i.e., decrease in retained austenite content) causes the increase in microhardness value.

In the HAZ, at the depth ranging from 250 to $500 \mu \mathrm{m}$, the microhardness is about $220 \mathrm{HV}_{0.2}$ and lower than that of the $\mathrm{MZ}$, but it is still higher than the substrate $\left(180 \mathrm{HV}_{0.2}\right)$. It is attributed to the partial transformation into martensite leading to intermediate microhardness. No notable softening from tempering by subsequent laser irradiation was found. 


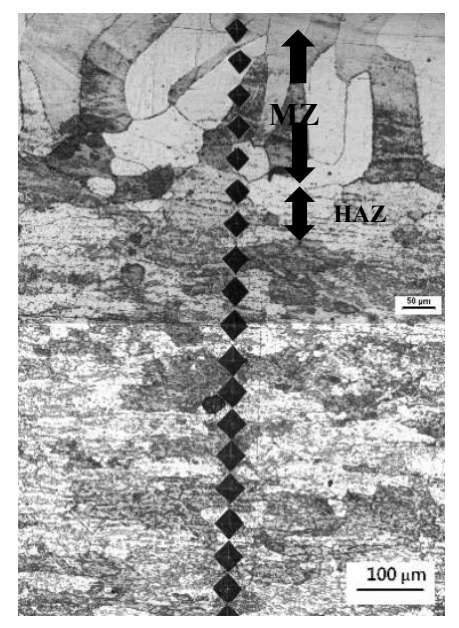

(a)

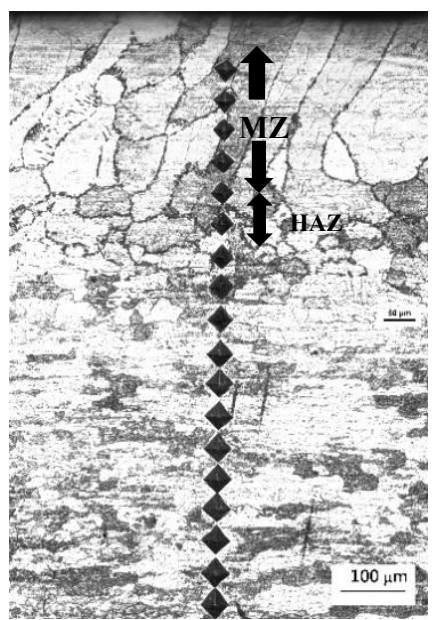

(b)

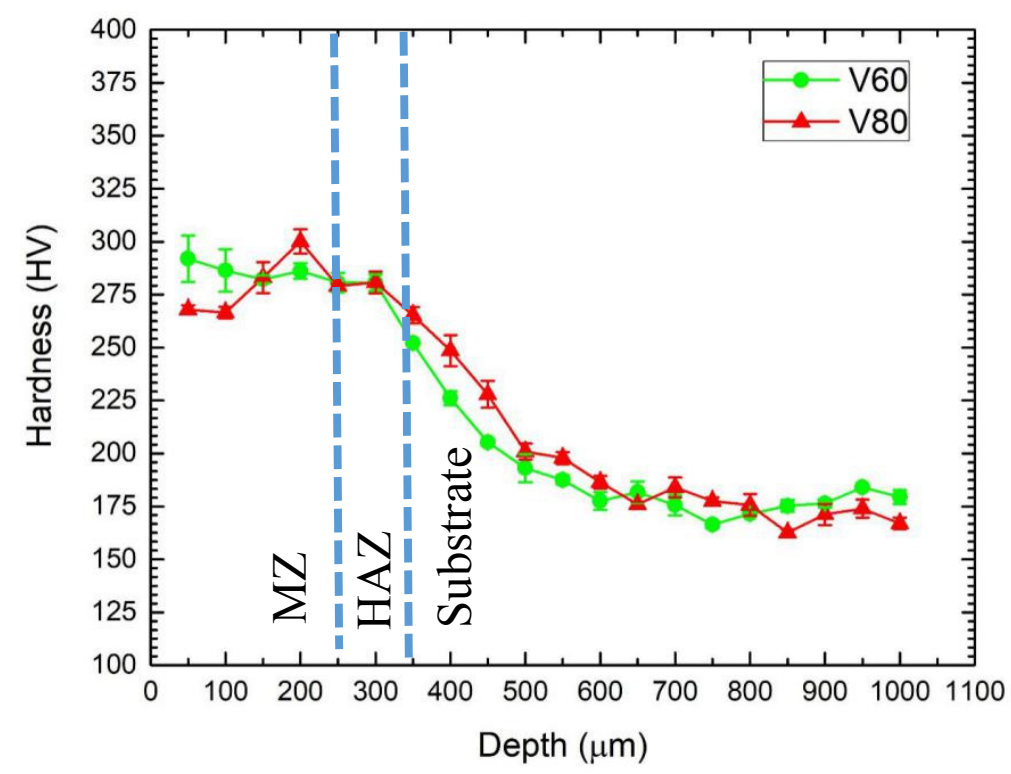

(c)

Figure 4. Microhardness measurement along the cross-sections of the laser-melted specimens (a) V60, (b) V80, and (c) their microhardness profiles.

\subsection{Tensile Properties}

The engineering stress vs. engineering strain curves for the as-received AISI 430 steel and laser-surface melted AISI 430 steel (V60 and V80) without and with hydrogen pre-charging are shown in Figure 5, and the corresponding mechanical parameters are tabulated in Table 4. Compared with the as-received AISI 430 steel, the yield strength of the laser-surface melted AISI 430 steel is similar and the tensile strength is increased by $8.6 \%-11.5 \%$, while the ductility is significantly reduced from 0.44 to $0.34-0.36$ (decrease by $20 \%$ ).

The ductility (strain to failure) of the as-received AISI 430 steel after hydrogen pre-charging was dramatically decreased from 0.44 to 0.25 (decreased by $43 \%$ ). The reason for the severe embrittlement is due to the high diffusivity of hydrogen atom in the $\alpha$-ferrite [24]. On the other hand, the tensile strength and ductility of the laser-surface melted AISI 430 steel after hydrogen pre-charging is reduced 
but the yield strength is similar as compared to the laser-surface melted AISI 430 steel without hydrogen pre-charging.

Increase in tensile strength for the laser-surface melted AISI 430 steel is due to strengthening via heating with the laser beam followed by rapid quenching leading to a formation of martensite. The corresponding values of $I_{\delta}$ for the as-received AISI 430 steel, V60 and V80, are tabulated in Table 4. A higher value of $I_{\delta}$ indicates a higher plastic loss after hydrogen charging, i.e., the as-received AISI 430 steel is more susceptible to HE. After LSM, the value of $I_{\delta}$ decreases from $43.2 \%$ to $38.9 \%$ and $38.2 \%$ for V60 and V80, respectively. From the EBSD results, the austenite contents of V60 and V80 are $0.6 \%$ and $1.9 \%$, respectively. As the content of austenite in the laser-surface melted AISI 430 steel is very low, the presence of austenite for reducing the hydrogen diffusion causes a minor effect on the HE susceptibility. A smaller $I_{\delta}$ value is obtained due to the presence of martensite, which is more susceptible to HE as compared to ferrite $[25,26]$. Table 4 compares the yield strength, tensile strength, ductility, and HE susceptibility $\left(I_{\delta}\right)$ for all samples. In the present study, the laser-surface melted specimens (V60 and V80) possessed higher microhardness (Figure 4) and lower HE susceptibility (Table 4) than those of the as-received AISI 430 steel. The decrease in HE susceptibility with microhardness was consistent with the finding of Sebastián et al. [27].

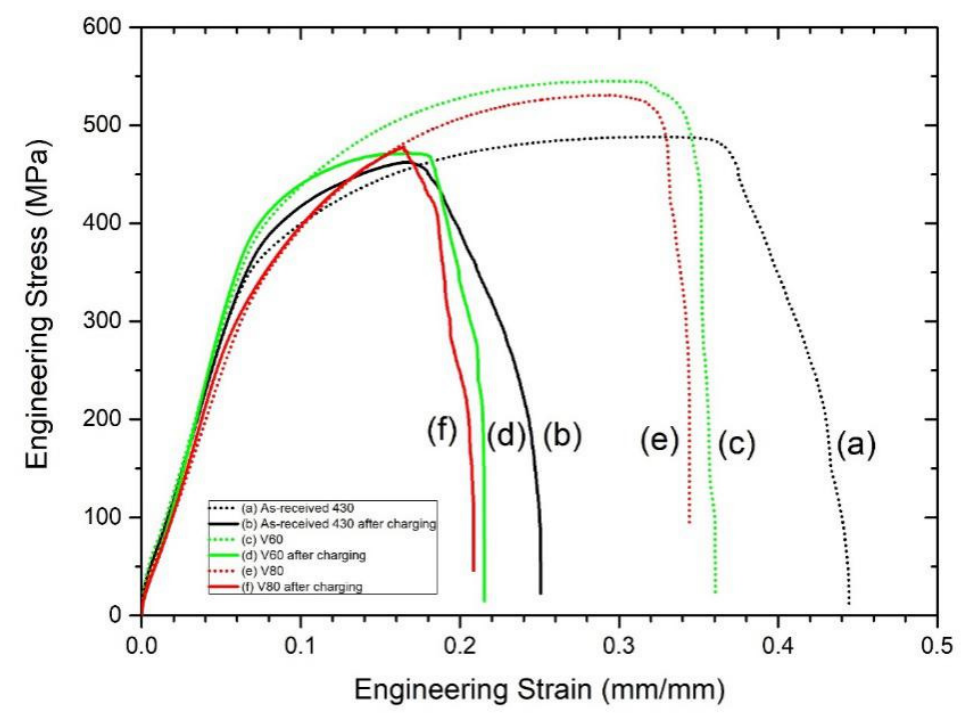

Figure 5. Stress-strain curves of (a) as-received AISI 430 steel, (b) hydrogen-charged AISI 430 steel for 1 week, (c) V60, (d) V60 hydrogen-charged for 1 week, (e) V80, (f) V80 hydrogen-charged for 1 week.

Table 4. Mechanical parameters of various specimens.

\begin{tabular}{|c|c|c|c|c|}
\hline & $\begin{array}{l}\text { Yield Strength } \\
\text { (MPa) }\end{array}$ & $\begin{array}{l}\text { Tensile Strength } \\
\text { (MPa) }\end{array}$ & $\begin{array}{c}\text { Ductility } \\
\text { (\% Elongation) }\end{array}$ & $\begin{array}{c}\text { HE Susceptibility } \\
\left(I_{\delta}\right)\end{array}$ \\
\hline (a) As-received AISI 430 steel & 348 & 488 & 0.44 & \multirow{2}{*}{$43.2 \%$} \\
\hline (b) As-received AISI 430 steel after charging & 364 & 462 & 0.25 & \\
\hline (c) V60 & 377 & 544 & 0.36 & \multirow{2}{*}{$38.9 \%$} \\
\hline (d) V60 after charging & 376 & 471 & 0.22 & \\
\hline (e) V80 & 326 & 530 & 0.34 & \multirow{2}{*}{$38.2 \%$} \\
\hline (f) V80 after charging & 327 & 474 & 0.21 & \\
\hline
\end{tabular}

\subsection{Fractography}

The fracture morphologies of the as-received AISI 430 steel without and with hydrogen pre-charging after tensile test are shown in Figure 6. Ductile fracture was observed for both specimens, although the ductility of the as-received AISI 430 steel was dropped after hydrogen pre-charging. Large microvoids or dimples on the fracture surface are observed and are the 
characteristics of the Hydrogen Enhanced Localized Plasticity (HELP) mechanism [28]. According to the plasticity model 'Hydrogen Enhanced Localized Plasticity (HELP)', which was first established by Beachem [29], the presence of hydrogen in the ferrite increases the mobility of dislocations and creates hydrogen-induced strain localizations. The hydrogen effect is the greatest at the crack tip where the local hydrogen concentration is increased by the effect of stress concentration. Hydrogen locally softens the material in front of the crack tip allowing ductile fracture to occur there, prior to general yielding in the bulk of material, away from the crack tip. When the crack initiates and propagates further, the stress concentration at the crack tip will increase [30]. When the crack tip meets the pile-up dislocation sites, brittle fracture will occur. At the microscopic level, plasticity is enhanced by hydrogen. On the other hand, at the macroscopic level, the material exhibits a brittle behavior [31]. The present result on HE is also supported by Malitckii and his co-workers [32], who reported that hydrogen led to significant plastic strain localization in the vicinity of the crack tips, and slip bands formed associated with deformation structures also followed the HELP mechanism.

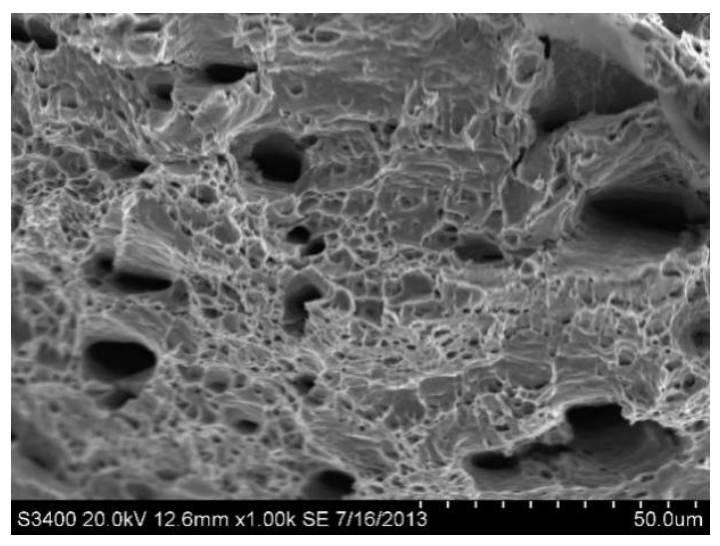

(a)

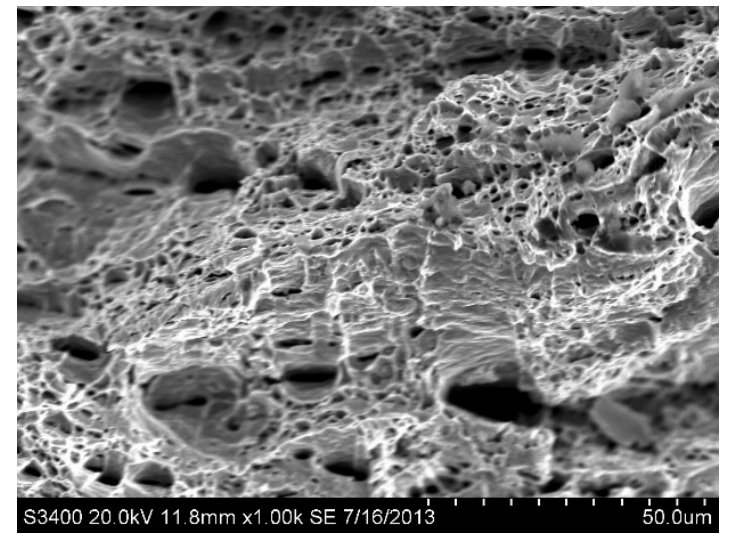

(b)

Figure 6. SEM fractographs of as-received AISI 430 steel (a) without hydrogen pre-charging; and (b) with hydrogen pre-charging.

For the laser-surface melted AISI 430 steel without and with hydrogen pre-charging, the fracture morphologies of the MZ [Figure 7a,b(i) and Figure 8a,b(i)] are different from that of the as-received AISI 430 steel. Brittle failures, including cleavage and intergranular fracture, are observed in the MZ, as shown in Figure $7 \mathrm{~b}$ (ii) and Figure $8 \mathrm{~b}$ (ii). Whereas ductile fracture can be seen at the substrate, as shown in Figure $77 \mathrm{~b}$ (iii) and Figure 8b(iii). With the presence of martensite, the HE susceptibility of V60 and V80 decreases [15,33]. The main fracture mode was a mixture of intergranular and quasi-cleavage fracture. This is in agreement with the observation of an intergranular phase $\left(\alpha^{\prime}\right.$ and $\gamma$ ) in the laser-surface melted specimens [Figure 2a(iii),b(iii)]. The existence of martensite is the most plausible explanation for the low toughness observed in such specimens. From Figure $7 \mathrm{~b}$ (ii), the regions with very small microvoids correspond to the ferrite grains, while the narrow-stripe regions consist of martensite. Figure 8b(ii) shows similar fracture morphology as Figure 7b(ii), which is the MZ of V80. From Figure $7 \mathrm{~b}$ (iii), a mixture of ductile and brittle fracture modes can be observed in the substrate, with the presence of cleavage (inside red box) and small dimples. The dimples are typically the HELP mechanism, where the size of the dimples is smaller after hydrogen charging compared to as-received AISI 430 steel. The cleavage area is slightly smaller in Figure 8b(iii) compared with Figure $7 b(i i i)$, and the dimples are larger compared with Figure $7 \mathrm{~b}$ (iii). The main reason is due to the more austenites formed in V60 and in V80 that reduce the effect of hydrogen embrittlement. The effect of LSM on fracture morphology dominates over the effect of hydrogen pre-charging for both V60 and V80. 


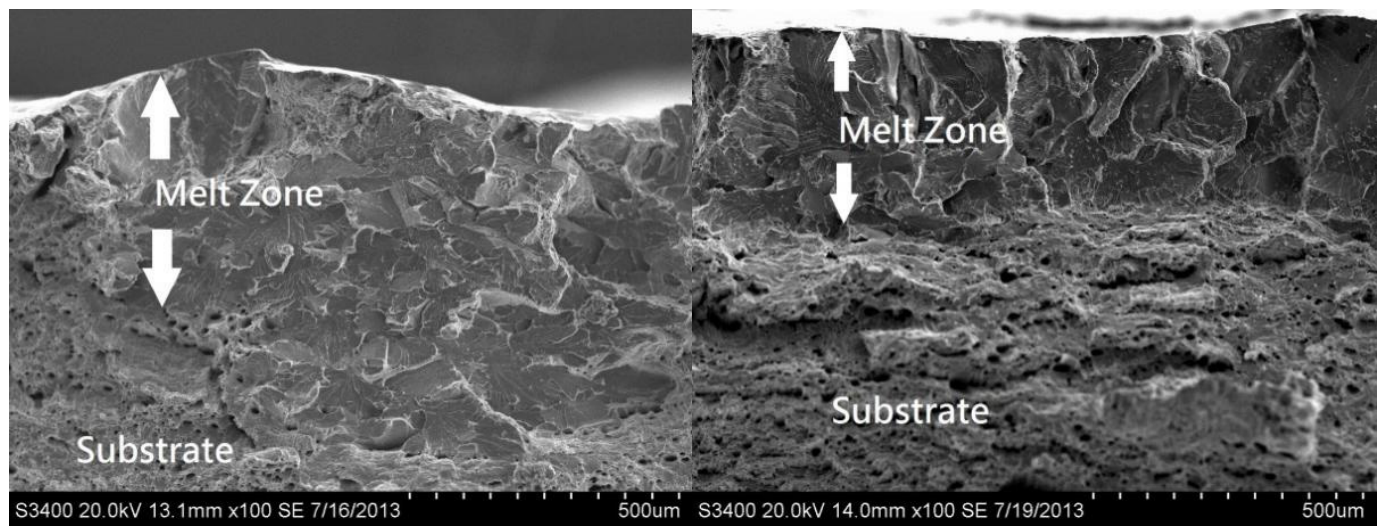

(a)

(b)(i)

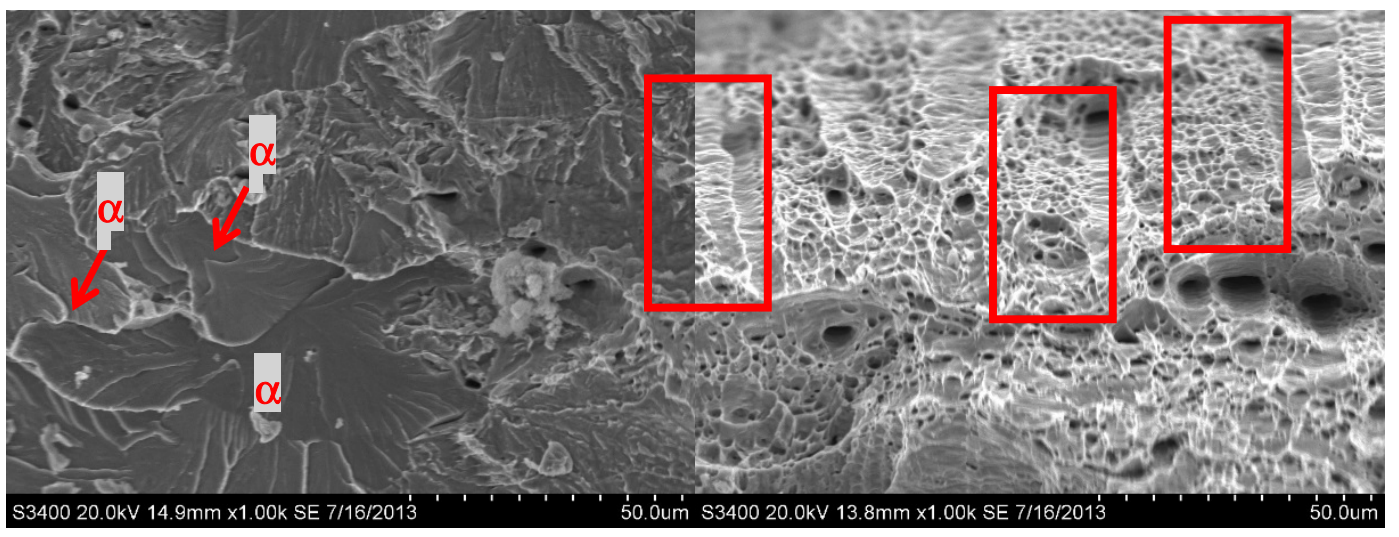

(b)(ii)

(b)(iii)

Figure 7. SEM fractographs of laser-surface melted AISI 430 steel (V60) (a) without hydrogen pre-charging; (b)(i) with hydrogen pre-charging, (b)(ii) MZ of (b)(i), and (iii) substrate of (b)(i).

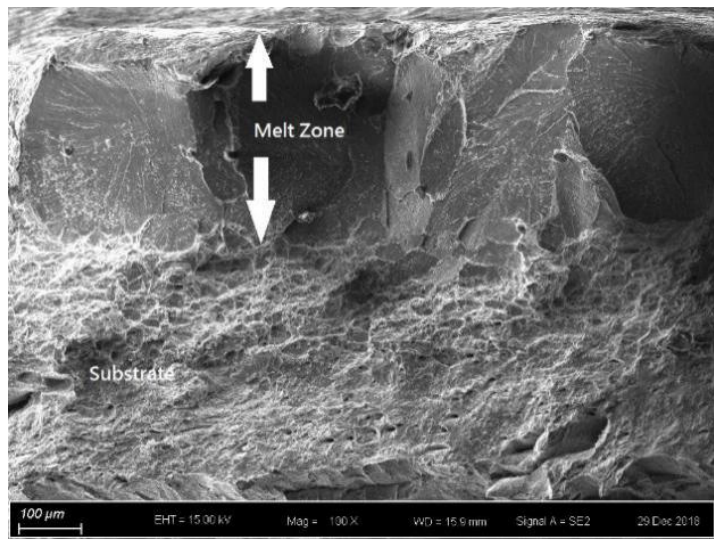

(a)

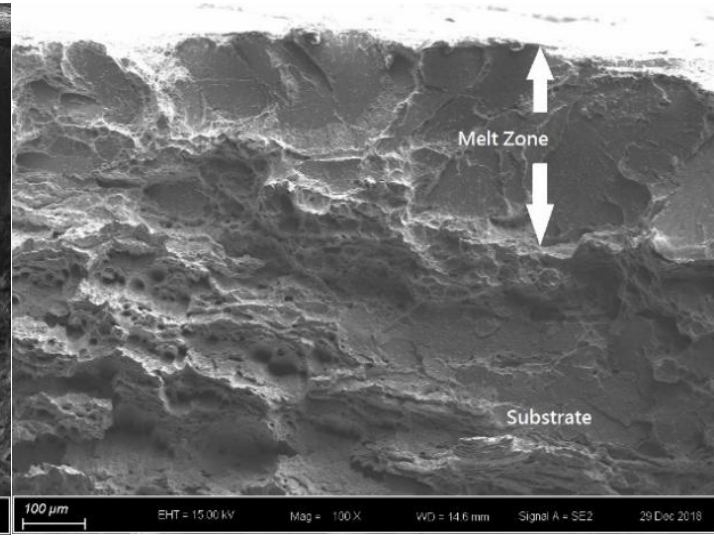

(b)(i)

Figure 8. Cont. 


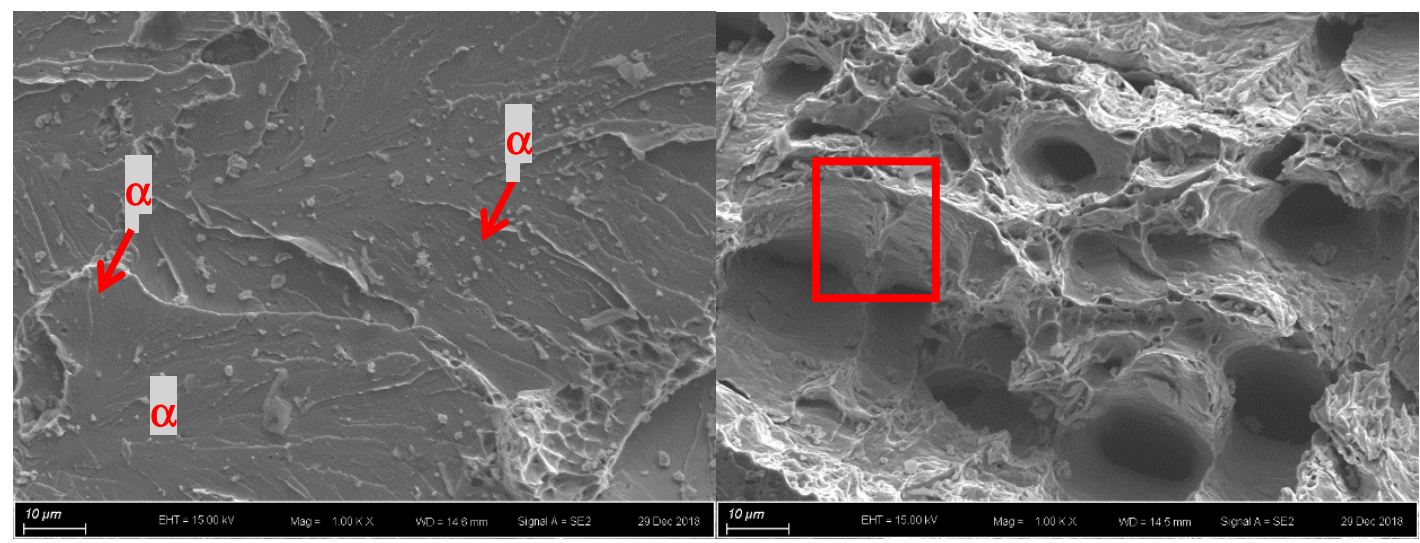

(b)(ii)

(b)(iii)

Figure 8. SEM fractographs of laser-surface melted AISI 430 steel (V80) (a) without hydrogen pre-charging, (b)(i) with hydrogen pre-charging, (b)(ii) MZ of (b)(i), and (iii) substrate of (b)(i).

\section{Conclusions}

- The austenite contents for the laser-surface melted samples V60 and V80 are found to be 0.6 and $1.9 \mathrm{wt} \%$, respectively. The amount of retained austenite reduces as the laser scanning speed decreases;

- At higher laser scanning speed, the quenching rate is higher resulting in more austenite. The microhardness at MZ and HAZ of laser-surface melted samples is about $270-280 \mathrm{HV}_{0.2}$ and $220 \mathrm{HV}_{0.2}$, respectively. Lower microhardness in V80 is due to a higher austenite content;

- After hydrogen pre-charging, the ductility of as-received AISI 430 steel was reduced from 0.44 to 0.25 , while the laser-surface melted AISI 430 steel showed similar tensile properties as the as-received one. After LSM, the value of hydrogen embrittlement susceptibility $I_{\delta}$ decreases from $43.2 \%$ to $38.9 \%$ and $38.2 \%$ for V60 and V80, respectively, due to the presence of martensite. The hydrogen embrittlement susceptibilities of both V60 and V80 decrease due to the presence of martensite;

- Brittle fracture is observed in the melt zone of the laser-surface melted AISI 430 steel, while ductile fracture is observed in the as-received AISI 430 steel. After LSM, the main fracture mode changes from intergranular to a mixture of intergranular and quasi-cleavage fracture. The austenite formed in V60 and V80 can lessen the effect of hydrogen embrittlement. The effect of LSM dominates over the effect of hydrogen pre-charging on fracture morphologies.

Author Contributions: Investigation, W.K.C., C.T.K. and K.H.L.; Supervision, C.T.K. and K.H.L.; Writing-original draft, W.K.C.; Writing-review \& editing, C.T.K. and K.H.L. All authors have read and agreed to the published version of the manuscript.

Funding: The present research was fully supported by the Multi-Year Research Grant (MYRG) of University of Macau [Grant number MYRG2018-00217-FST].

Acknowledgments: Support from the infrastructure of University of Macau is acknowledged.

Conflicts of Interest: The authors declare no conflict of interest.

\section{References and Note}

1. Timothy, T.M.; Hwang, S.J.; Bowman, R.C.; Birkmire, D.S.; Jense, C.M.; Udovic, T.J.; Conradi, M.S. Discovery of a new $\mathrm{Al}$ species in hydrogen reactions of $\mathrm{NaAlH}_{4}$. J. Phys. Chem. Lett. 2010, 1, 2412-2416.

2. Riecke, E. Wasserstoff in Eisen und Stahl. Arch. Für Das Eisenhüttenwesen 1978, 49, 509-520. [CrossRef]

3. Hofmann, W.; Rauls, W. Ductility of Steel Under the Influence of External High Pressure Hydrogen. Weld. Res. Suppl. 1965, 44, 225-230. 
4. Frick, V.; Janser, G.R.; Brown, J.A. Space Shuttle Mater. 1971, Sampe, Azusa 3. 579-634.

5. Fukuyama, S.; Sun, D.; Zhang, L.; Wen, M.; Yokogawa, K. Effect of temperature on hydrogen environment embrittlement of type 316 series austenitic stainless steels at low temperatures. J. Jpn. Inst. Met. 2003, 67, 456-459. [CrossRef]

6. Abdalla, A.M.; Hossain, S.; Nisfindy, O.B.; Azad, A.T.; Dawood, M.; Azad, A.K. Hydrogen production, storage, transportation and key challenges with applications: A review. Energy Convers. Manag. 2018, 165, 602-627. [CrossRef]

7. Owczarek, E.; Zakroczymski, T. Hydrogen transport in a duplex stainless steel. Acta Mater. 2000, 48, 3059-3070. [CrossRef]

8. Zakroczymski, T.; Owczarek, E. Electrochemical investigation of hydrogen absorption in a duplex stainless steel. Acta Mater. 2002, 50, 2701-2713. [CrossRef]

9. Michler, T.; Naumann, J. Coatings to reduce hydrogen environment embrittlement of 304 austenitic stainless steel. Surf. Coat. Technol. 2009, 203, 1819-1828. [CrossRef]

10. Kwok, C.T. Laser Surface Modification of Alloys for Corrosion and Erosion Resistance; Woodhead Publishing: Sawston, Cambridge, UK, 2012; pp. 3-40.

11. Ready, J.F.; Farson, D.F.; Feeley, T. LIA Handbook of Laser Materials Processing; Springer-Verlag: Orlando, FL, USA, 2001; pp. 273-279.

12. Conde, A.; Colaco, R.; Vilar, R.; de Damborenea, J. Corrosion behaviour of steels after laser surface melting. Mater. Des. 2000, 21, 441-445. [CrossRef]

13. Zakroczymski, T.; Glowacka, A.; Swiatnicki, W. Effect of hydrogen concentration on the embrittlement of a duplex stainless steel. Corros. Sci. 2005, 47, 1403-1414. [CrossRef]

14. ASTM G129-00 (2013). Standard Practice for Slow Strain Rate Testing to Evaluate the Susceptibility of Metallic Materials to Environmentally Assisted Cracking; ASTM International: West Conshohocken, PA, USA, 2013.

15. Fan, Y.H.; Zhang, B.; Yi, H.L.; Hao, G.S.; Sun, Y.Y.; Wang, J.Q.; Hana, E.H.; Ke, W. The role of reversed austenite in hydrogen embrittlement fracture of S41500 martensitic stainless steel. Acta Mater. 2017, 139, 188-195. [CrossRef]

16. Castro, R.; Tricot, R. Études des transformations isothermes dans les aciers inoxydables semi-ferritiques á 17\% de chrome. Mem. Sci. De La Rev. De Metall. 1962, 59 (Pt 1), (Pt 2), 571-586, 587-596.

17. David, S.A.; Vitek, J.M.; Hebble, T.L. Effect of rapid solidification on stainless steel weld metal microstructures and its implication on the Schaffler diagrams. Weld. J. 1987, 66, 289-300.

18. Delong, W.T.; Ostrom, G.A.; Szumachowski, E.R. Measurement and calulation of ferrite in stainless steel Weld Metal. Weld. J. 1956, 35, 526-533.

19. Kaltenhauser, R.H. Improving the engineering properties of ferritic stainless steels. Met. Eng. Q. 1971, 11, 41-47.

20. Balmforth, M.C.; Lippold, J.C. A new ferritic-martensitic stainless steel constitution diagram. Weld. J. 2000, 79, 339-345.

21. Colacë O, R.; Vilar, R. Effect of the processing parameters on the proportion of retained austenite in laser surface melted tool steel. J. Mater. Sci. Lett. 1998, 17, 563-567. [CrossRef]

22. Sundqvist, J.; Manninen, T.; Heikkinen, H.P.; Anttila, S.; Kaplan, A.F.H. Laser surface hardening of $11 \% \mathrm{Cr}$ ferritic stainless steel and its sensitization behavior. Surf. Coat. Technol. 2018, 344, 673-679. [CrossRef]

23. Khorram, A.; Jamaloei, A.D.; Jafari, A.; Moradi, M. Nd:YAG laser surface hardening of AISI 431 stainless steel; mechanical andmetallurgical investigation. Optics Laser Technol. 2019, 119, 105617. [CrossRef]

24. Nelson, H.G.; Stein, J.E. Gas-phase Hydrogen Permeation through Alpha Iron, 4130 Steel, and 304 Stainless Steel from less than $100{ }^{\circ} \mathrm{C}$ to near $600^{\circ} \mathrm{C}$. NASA TN D-7265; Ames Research Center, National Aeronautics and Space Administration: Moffett Field, CA, USA, April 1973.

25. Tavares, S.S.M.; da Silva, G.F.; Parda, J.M.; Silva, M.R.; de Abreu, H.F.G. Influence of heat treatments on toughness and sensitization of a Ti-alloyed supermartensitic stainless steel. J. Mater. Sci. 2011, 46, 7737-7747.

26. Gesnouin, C.; Hazarabedian, A.; Bruzzoni, P.; Ovejero-Garcia, J.; Bilmes, P.; Llorente, C. Effect of post-weld heat treatment on the microstructure and hydrogen permeation of $13 \mathrm{CrNiMo}$ steels. Corros. Sci. 2004, 46, 1633-1647. [CrossRef]

27. Sebastián, Z.; Estela, S.; Hernán, S. Effects of welding procedure on corrosion resistance and hydrogen Embrittlement of supermartensitic stainless steel deposits. J. Iron Steel Res. Int. 2013, 20, 124-132. [CrossRef] 
28. Tavares, S.S.M.; Bastos, I.N.; Pardal, J.M.; Montenegro, T.R.; da Silva, M.R. Slow strain rate tensile test results of new multiphase $17 \% \mathrm{Cr}$ stainless steel under hydrogen cathodic charging. Int. J. Hydrog. Energy 2015, 40, 16992-16999. [CrossRef]

29. Beachem, C.D. A new model for hydrogen assisted cracking (hydrogen embrittlement). Metall. Mater. Trans. 1972, A3, 437-451. [CrossRef]

30. Ohmura, T.; Minor, A.M.; Stach, E.A.; Morris, J.W. Dislocationegrain boundary interactions in martensitic steel observed through in situ nanoindentation in a transmission electron microscope. J. Mater. Res. 2004, 19, 3626-3632. [CrossRef]

31. Eastman, J.; Matsumoto, T.; Narita, N.; Heubaum, F.; Birnbaum, H.K. Hydrogen in Metals; Bernstein, I.M., Thompson, A.W., Eds.; TMS: New York, NY, USA, 1981; pp. 397-409.

32. Malitckii, E.; Yagodzinskyy, Y.; Lehto, P.; Remes, H.; Romu, J.; Hänninen, H. Hydrogen effects on mechanical properties of $18 \% \mathrm{Cr}$ ferritic stainless steel. Mater. Sci. Eng. A 2017, 700, 331-337. [CrossRef]

33. Li, X.; Zhang, J.; Chen, J.; Shen, S.; Yang, G.; Wang, T.; Song, X. Effect of aging treatment on hydrogen embrittlement of PH 13-8 Mo martensite stainless steel. Mater. Sci. Eng. 2016, A651, 474-485. [CrossRef]

(C) 2020 by the authors. Licensee MDPI, Basel, Switzerland. This article is an open access article distributed under the terms and conditions of the Creative Commons Attribution (CC BY) license (http://creativecommons.org/licenses/by/4.0/). 